\title{
Malaria control: Knowledge and Practice among Over-the-Counter Medicine Sellers in the Pru, Sene and Atebubu-Amantin Districts, Brong Ahafo Region, Ghana
}

\author{
Article by Mensah S.J.A ${ }^{1}$., Addai-Mensah $\mathrm{O}^{2}$., Nagai. H. $\mathrm{N}^{3}$ \\ ${ }^{1}$ School of Clinical Research, Texila American University, Guyana \\ ${ }^{2}$ Faculty of Allied Health Sciences, Kwame Nkrumah University of Science and \\ Technology, Kumasi, Ghana \\ ${ }^{3}$ UNAIDS, Accra, Ghana \\ Email: profhenson@yahoo.com
}

\begin{abstract}
Background: Malaria continues to be a major health burden worldwide. In Ghana, Over-the-Counter (OTC) medicine sellers and community pharmacies are known private medicine outlets patients access for malaria treatment. The aim of this study was to assess the knowledge and practice on malaria control among OTC medicine sellers in the Pru, Sene West and East and Atebubu-Amantin districts in the Brong Ahafo region of Ghana. Method: A cross-sectional descriptive study was conducted using a structured questionnaire. Sixty-two (62) OTC medicine sellers were randomly selected, informed consent sought and interviewed on malaria transmission, symptoms, prevention, diagnosis and treatment, antimalarial medicine stock and malaria training participated in. Data entry, editing and analysis were done using SPSS. Results: The study revealed a high knowledge on malaria transmission vector, symptoms and prevention with $63 \%$ of the OTC medicine sellers have participated in at least one malaria training organized either by the Pharmacy council and/or partners within the past two years. Only $26.2 \%$ of OTC medicine sellers use the malaria rapid diagnostic test (RDT) kit to diagnosis and confirm suspected malaria. Majority (65.6\%) of OTC medicine sellers often recommend Artemether Lumefantrine (AL) to patients to treat uncomplicated malaria, with between $26 \%$ to $43.5 \%$ of them haven herbal preparations, sulphadoxine pyrimethamine (SP), monotherapies (only artesunate, or only amodiaquine or only artemether or only lumefantrine) and quinine as the alternative antimalarial medicines at the shop. Most OTC medicine sellers do not comply with the national antimalarial drug treatment guidelines. There was a significant difference $(p<0.05)$ between the malaria management knowledge and skills of a trained OTC medicine seller and a non trained one. Conclusion: Trained OTC medicine sellers have better malaria management knowledge and skills than the non -trained ones. Recommendation: Periodic malaria training of all OTC medicine sellers which focuses on effective diagnosis and treatment would significantly improve the knowledge and the skills in malaria management and control among OTC medicine sellers at the community level.
\end{abstract}

Keywords: Malaria, Knowledge, Practice, OTC medicine seller, Pru, Sene, Atebubu-Amantin

\section{Introduction}

Malaria continues to be a major health burden worldwide. In 2015, 214 million estimated cases and 438,000 deaths from malaria were reported (WHO malaria report, 2015). Ninety-one percent of these malaria cases were due to infection with P. Falciparum. Malaria remains a major killer of children, particularly in sub-Saharan Africa, taking the life of a child every 2 minutes (WHO malaria report 2015). In many developing countries and in Africa especially, malaria exacts an enormous toll on life, not only in medical costs (Addai-Mensah, 2014), but also in days of labor lost.

In Ghana, malaria contributes significantly to ill health as well as infant and maternal deaths. Malaria is known to account for about $40-50 \%$ of outpatient consultations in hospitals 
and clinics, and also contributes directly to low productivity, reduced school attendance and poor academic performance among school children in Ghana ( Goodman et al 2007a). Recent strategies to combat malaria, led by the World Health Organization's "Roll Back Malaria" initiative, include early and effective treatment. Such strategies highlight the role of private medicine retailers to promote early effective home treatment of childhood malaria in endemic settings (WHO, 2005). As part of efforts to improve access to prompt treatment, particularly in isolated rural areas, community-level interventions which seek to strengthen home management of children with fever are gaining importance. Private pharmaceutical facilities are the main points of call for the management of uncomplicated malaria in sub-Saharan Africa (Danquah, 2010) .

\subsection{Over-the-counter (OTC) medicine seller in malaria control in Ghana}

In Ghana, OTC Medicine Sellers' shops are the principal source of medicinal products for the Ghanaian rural population. A Licensed OTC Medicine seller is a private provider who has obtained the appropriate license from the Pharmacy Council, which authorizes him or her to engage in the retail of only Over-the-Counter drugs (Class C or OTC drugs) at a premises or location specified in the license ( Pharmacy Act, 1994 -ACT 489). According to Ghana National Over-the-Counter Medicine sellers Association there are estimated 13,000 OTC Medicine Sellers in Ghana, who are members of the National OTC Medicine Sellers association. Selection exercises conducted by FHI 360 malaria team in 2015 indicated there are over 100 OTC medicine sellers in the Pru, Sene and Atebubu-Amantin districts.

Studies conducted by Goodman et al 2007a, Smith 2004 and Van den Boom et al 2004, on health seeking behaviour among Ghanaians suggested that, community pharmacies and licensed chemical shops were usually the first port of call for health advice and treatment for many individuals with symptoms suggestive of malaria. The Mobilize against Malaria project baseline report 2008 indicated that OTC Medicine Sellers are recognized as the first-line or only source of consultation for 60 percent of people seeking health care in general. The explanation given for this observation was that, those community-based retail outlets operated for long hours, were not charging consultation fees, and patrons did not have to wait for long hours before having access to practitioners to purchase anti-malarials. The retail practitioners were also perceived to be friendlier, and payments for anti-malaria services were flexible for known community members (Ahorlu et al 1997, Goodman et al 2007a, Smith 2009b).

Therefore knowledge and practice of OTC medicine sellers in malaria management, prevention and control are crucial to the fight against malaria at the community level.

To date, little research has been done to document the knowledge and practice on malaria case management among OTC medicine sellers and its effect in malaria control in Ghana. This means the role of Over-the-Counter Medicine Sellers in Ghana has less been exploited. The objective of this study was to assess the malaria knowledge and practice among over-the -Counter Medicine Sellers in the Brong Ahafo region

\section{Methods}

\subsection{Study design}

A cross-sectional descriptive study was conducted in the Pru, Sene and Atebubu-Amantin districts of the Brong Ahafo Region of Ghana among trained and untrained Over-the-Counter Medicine Sellers to evaluate their knowledge and practice on malaria case management and access to Artemisinin-based Combination Therapy.

\subsection{Study area}

Pru, Atebubu-Amantin and Sene districts are rural districts in the Brong Ahafo region of Ghana. They are predominately rural with large tracts of forest, many water bodies, high vector density for malaria, poor sanitation, with communities that are generally at high risk of malaria. The districts are hyper-endermic for malaria with a prevalence of $70-90 \%$ (NMCP report 2008). There are few Health facilities in the districts, this also accounts for high 
patronage of the services of the OTC medicine sellers. There are over 100 OTC sellers operating in these rural districts.

\subsection{Sampling method}

A list of Over-the-Counter Medicine sellers was obtained from the Association Executives and also FHI 360 OTC Medicine sellers identification exercise indicates a total of 106 OTC Medicine sellers ( Pru -21, Sene -34 Atebubu-Amantin -51). Sixty-two (62) OTC Medicine Sellers was randomly selected, informed consent was sought and interviewed.

\subsection{Data collection tools, processing and analysis 2.4.1 structured questionnaire and inform consent form}

Informed consent was sought from the OTC Medicine sellers after which structured questionnaires was administered to the respondents at the OTC Medicine Shop. The interviews were conducted by four trained data collectors from March 5 to 12, 2016. The interviews sought to elicit information on the knowledge and skills of the OTC medicine Seller in malaria causes, transmission, signs and symptoms recognition, disease prevention, tools or criteria for diagnosis, treatment regimen, availability of Rapid Diagnostic Test kit, availability of Artemisinin-based Combination Therapy in the shop and malaria training participated within the past two years.

\subsubsection{Data processing and analysis}

Statistical Package for Social Sciences (SPSS) version 16 was used to enter, edit and analyze the data quantitatively. The necessary graphics and tables were drawn. Inferences were then drawn from the analysis.

\subsection{Ethical considerations}

Ethical approval (CHRPE/AP/038/16) was sought from the Committee on Human Research, Publication and Ethics (CHRPE) - the Kwame Nkrumah University of Science and Technology (KNUST) on Research Involving Human Subjects. Permission was also sought from the Pru, Sene West and Atebubu-Amantin District Directors of Health Services, and the Districts OTC medicine sellers Associations. The research participants were OTC medicine sellers who gave their informed consent and voluntarily participated. Privacy, confidentiality and anonymity were assured and ensured. Participants were not compensated for the information provided.

\section{Results}

\subsection{Demographic characteristics of respondents}

Sixty two (62) respondents consented and were interviewed. About $47 \%$ of the respondents were shop owners and 53\% were shop assistants. Majority of the respondents were males, 52 $(83.9 \%)$. The females constitute $16.1 \%$ (10) of the total respondents, and accounted for $27.3 \%(9)$ of the shop assistants and 3.4\%(1) of the shop owners. Most of the respondents were within the age group $20-39$ years $(58.1 \%)$. There was no OTC medicine seller under 18 years of age. 23 of the respondents, representing $37.1 \%$ were within the age range $40-59$ years, with only one person (1.6\%) been above 60 years ( 62 years). $72.2 \%$ of respondents within the $20-39$ years age group were shop assistants and $82.6 \%$ of respondents within the $40-59$ years age group were shop owners. Forty one (66.1\%) respondents were senior secondary/high school certificate (S.S.S.C.E) holders. Seven (11.3\%) were Middle School Leaving Certificate (MSLC) holders. About $16.1 \%, 4.8 \%$ and $1.6 \%$ of the respondents were Tertiary, Junior High School and Technical/Vocational school certificate holders respectively. Over $63.4 \%$ (26) of the respondents with SHS certificates were shop assistants. Six out of the ten $(60 \%)$ tertiary certificate holders were shop owners.46.8\% (29/62) of the respondents were Pharmacy Council trained OTC medicine sellers and 35.5\% (22/62) were trained counter assistants. $17.8 \%$ $(11 / 62)$ were neither trained OTC medicine sellers nor counter assistants. Over $70 \%$ of the non trained OTC Medicines Sellers were Senior High school leavers who completed school within 
South American Journal of Clinical Research

Volume 3, Issue 1, 2016

the past 1 to 5 years. The average years of experience of owners versus assistants were 13.2 years to 7.4 years. Over $75 \%$ of the owners had been working as OTC Medicine Sellers for more than 10 years. See Table 1 for demographic characteristics of respondents

\subsection{Malaria training participation within the past 2 years}

39 respondents $(63 \%)$ had participated in at least one malaria training workshop within the past two years $(2013,2014$ and 2015). Out of this number, 87.2\% (34) participated in the Malaria Control and Case Management workshop organized by the USAID funded Strengthening Health Outcomes in Private Sectors (SHOPS) project in collaboration with Pharmacy council in 2014. About 69\% (20) of owners and 56\% (18) of assistants had participated in malaria training within the past two years (table 1).

\subsection{Malaria knowledge and practice}

\subsubsection{Malaria transmission, prevention and diagnosis}

About 68\% (42) and 29\% (18) respondents answered: "bite of an infected anopheles mosquito" and "bite of a mosquito" as the means by which one gets malaria. Two respondents answered "living in a dirty environment"; representing 3.2\% of the number of respondents interviewed. There was no statistically significant difference $(p>0.05)$ between the response of people who had participated in malaria training within the past two years and those who had not.

Approximately 50\% (56) of the respondents advice clients and patients to prevent malaria by $\mathrm{w}$ "sleeping in long lasting insecticidal treated nets (LLIN)". 23\%, 17.7\% and 9.7\% of the responses were "spray and repellent, weed the surroundings and draining stagnant water bodies and gutters" respectively. There was no statistically significant difference ( $p>0.05)$ between the response of people who had participated in malaria training within the past two years and those who had not. 54.1\% (33/61) and 26.2\% (16/61) of respondent uses "Clinical symptoms and Rapid Diagnostic Test (RDT) kits" respectively to diagnose malaria. About $5 \%(2)$ uses "Malaria Job Aid" to diagnose malaria and almost 8\% (3) uses "Assumption" to diagnose malaria. Over $30 \%$ ( 7 out of 23 ) of the respondents who had not participated in any malaria training within 2013 and 2015, use Assumption to diagnose malaria. None of the respondents who had never participated in malaria training within 2013 and 2015 uses Malaria Job aid to help diagnose malaria. There was a significant difference $(p<0.05)$ between the responses of respondents who had participated in malaria training within 2013 and 2015 and those who had not in relation to the following methods of diagnosing malaria; "RDT" "Assumption" and "Malaria Job aid"

Table1. Demographic characteristics of respondent

\begin{tabular}{|c|c|c|c|}
\hline Variable & $\begin{array}{l}\text { Trained in malaria } \\
\text { control in past } 2 \\
\text { yrs }[\mathrm{N} 1=38] * 1 \\
\text { missing }\end{array}$ & $\begin{array}{l}\text { Untrained in } \\
\text { malaria control in } \\
\text { past } 2 \text { yrs } \\
{[\mathrm{N} 2=23]}\end{array}$ & $\begin{array}{l}\text { Total } \\
{[\mathrm{N}=62]}\end{array}$ \\
\hline \multicolumn{2}{|l|}{ Freq. (\%) } & Freq. $(\%)$ & Freq. $(\%)$ \\
\hline \multicolumn{4}{|l|}{ Sex } \\
\hline Male & $34(89.5)$ & $18(78.3)$ & $52(83.9)$ \\
\hline Female & $4(10.5)$ & $6(26.1)$ & $10(16.1)$ \\
\hline \multicolumn{4}{|c|}{ Age groups (years) } \\
\hline $18-19$ & $1(2.6)$ & $1(4.3)$ & $2(3.2)$ \\
\hline $20-39$ & $23(60.5)$ & $13(56.5)$ & $36(58.1)$ \\
\hline $40-59$ & $14(36.8)$ & $9(39.1)$ & $23(37.1)$ \\
\hline$\geq 60$ & $0(0)$ & $1(4.3)$ & $1(1.6)$ \\
\hline \multicolumn{4}{|c|}{ Formal educational level } \\
\hline JHS & $2(5.3)$ & $1(4.3)$ & $3(4.8)$ \\
\hline MSLC & $3(7.9)$ & $4(17.4)$ & $7(11.3)$ \\
\hline
\end{tabular}




\begin{tabular}{|l|l|l|l|}
\hline Sec./SHS & $25(65.8)$ & $16(69.6)$ & $41(66.1)$ \\
\hline Tech/Voc. & $1(2.6)$ & $0(0)$ & $1(1.6)$ \\
\hline Tertiary & $8(21.1)$ & $2(8.7)$ & $10(16.1)$ \\
\hline Respondent status & $20(52.6)$ & $9(39.1)$ & $29(47.0)$ \\
\hline Shop Owner & $18(47.4)$ & $15(22.1)$ & $42(21.8)$ \\
\hline Shop Assistant & Qu & $29(47.0)$ \\
\hline $\begin{array}{l}\text { Qualification of Respondent } \\
\text { OTC Trained }\end{array}$ & $20(52.6)$ & $9(39.1)$ & $22(35.5)$ \\
\hline $\begin{array}{l}\text { Counter } \\
\text { Assistant }\end{array}$ & $15(39.5)$ & $7(30.4)$ & $10(16.1)$ \\
\hline $\begin{array}{l}\text { Not Qualified } \\
\text { OTCMS }\end{array}$ & $3(7.9)$ & $7(30.4)$ & \\
\hline
\end{tabular}

Table 2. PC-Pharmacy council OTCMS - OTC medicine seller

See Table 2 for details.

\subsubsection{Rapid diagnostic test kit (RDT) training, possession, supply/access and price}

Forty one (41) out of 61 respondents $(67.2 \%)$ had been trained on how to use malaria RDT kit to diagnose malaria. Out of this number $41.5 \%$ (17) had malaria RDT kit at the Shop at the time of the interview (Table 2). Some reason attributed for the unavailability of the malaria RDT kit at the time of the interview include: "stock out", "low patronage of the RDT by client because of the price", and "the inconsistency in the supply of RDT by the suppliers" $26.2 \%$ (16/61) of respondents buy their malaria RDT kits from the Pharmacy shops and the National Malaria Control Program (NMCP). Only one respondent procured the kit through the District OTC Medicine Sellers Association. The average whole sale price per cassette of a malaria RDT kit was One Ghana cedi forty five peswas; GH $\quad 1.45 \pm 0.16$ (equivalent to USD \$ $0.37 \pm 0.04$ ) and the average retail price per cassette of a malaria RDT kit was Two Ghana cedi four peswas GH $2.04 \pm 0.13$ (USD \$ 0.53 \pm 0.03 ) -Figure 1. [ Exchange rate GH $3.85=$ USD $\$ 1.00$ ]

Average Wholesale and Retail prices of malaria RDT

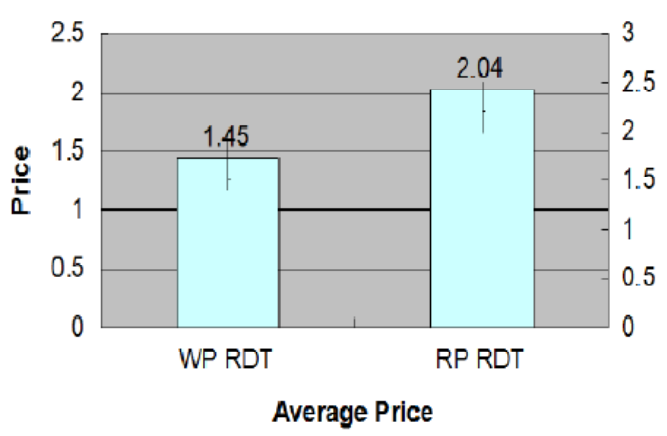

Figure 1. Average Wholesale and Retail Prices of malaria RDT

\subsubsection{Knowledge about intermittent preventive therapy for pregnant women}

$75.4 \%(46 / 61)$ of respondents had heard about 
South American Journal of Clinical Research

Volume 3, Issue 1, 2016

Table 3. Responses on Malaria knowledge and Practice among Respondents

\begin{tabular}{|c|c|c|c|}
\hline Variable & $\begin{array}{l}\text { Trained in } \\
\text { malaria control } \\
\text { in past } 2 \text { yrs }\end{array}$ & $\begin{array}{l}\text { Untrained in } \\
\text { malaria control } \\
\text { in past } 2 \mathrm{yrs}\end{array}$ & Total \\
\hline \multicolumn{2}{|l|}{ Freq. (\%) } & Freq. (\%) & Freq. $(\%)$ \\
\hline \multicolumn{4}{|l|}{ Malaria Transmission } \\
\hline & $\mathrm{N} 1=38$ & $\mathrm{~N} 2=23$ & $\mathrm{~N}=62$ \\
\hline Bite of a mosquito & $9(23.7)$ & $9(39.1)$ & $18(29.0)$ \\
\hline $\begin{array}{l}\text { Bite of an infected } \\
\text { female mosquito }\end{array}$ & $28(73.7)$ & $14(60.9)$ & $42(68.9)$ \\
\hline $\begin{array}{l}\text { Living in dirty } \\
\text { environment }\end{array}$ & $1(2.6)$ & $1(4.3)$ & $2(3.2)$ \\
\hline \multicolumn{4}{|l|}{ Malaria Prevention } \\
\hline Responses & $\mathrm{N} 1=73$ & $\mathrm{~N} 2=40$ & $\mathrm{~N}=113$ \\
\hline Sleep in LLIN & $35(47.9)$ & $21(52.5)$ & $56(49.6)$ \\
\hline $\begin{array}{l}\text { Use mosquito spray } \\
\text { and repellent }\end{array}$ & $18(24.7)$ & $8(20)$ & $26(23)$ \\
\hline Weed the surrounding & $12(16.4)$ & $8(20)$ & $20(17.7)$ \\
\hline $\begin{array}{l}\text { Drain stagnant waters } \\
\text { and gutters }\end{array}$ & $8(11)$ & $3(7.5)$ & $11(9.7)$ \\
\hline \multicolumn{4}{|c|}{ Malaria Diagnosis practice } \\
\hline & $\mathrm{N} 1=38$ & $\mathrm{~N} 2=23$ & $\mathrm{~N}=61$ \\
\hline $\begin{array}{l}\text { Use Clinical } \\
\text { symptoms }\end{array}$ & $20(52.6)$ & $13(56.5)$ & $33(54.1)$ \\
\hline Use RDT & $13(34.2)$ & $3(13.0)$ & $16(26.2)$ \\
\hline $\begin{array}{l}\text { Assumption/presumpti } \\
\text { on }\end{array}$ & $3(7.9)$ & $7(30.4)$ & $10(16.4)$ \\
\hline Malaria job aid & $2(5.3)$ & $0(0)$ & $2(3.3)$ \\
\hline \multicolumn{4}{|l|}{ Malaria RDT trained } \\
\hline & $\mathrm{N} 1=38$ & $\mathrm{~N} 2=23$ & $\mathrm{~N}=61$ \\
\hline Yes & $33(86.8)$ & $8(34.6)$ & $41(67.2)$ \\
\hline No & $5(13.2)$ & $15(65.2)$ & $20(32.8)$ \\
\hline \multicolumn{4}{|c|}{ Had malaria RDT at Shop } \\
\hline & $\mathrm{N} 1=38$ & $\mathrm{~N} 2=23$ & $\mathrm{~N}=61$ \\
\hline Yes & $13(34.2)$ & $4(17.4)$ & $17(27.9)$ \\
\hline No & $25(65.8)$ & $19(82.6)$ & $44(72.1)$ \\
\hline
\end{tabular}

IPT for pregnant women and know SP and SP-doxycycline has the drugs given to pregnant women for IPT. Out of this number, $87 \%(40 / 46)$ were able to accurately explained what is involved in IPT for pregnant women 78.7\% (48/61) of respondents often advice to pregnant women who report to their shops for malaria treatment. $11.5 \%(7 / 61)$ of respondents give them SP to treat suspected malaria in pregnant women. 9.8\% (6/61) of respondents do not provide advice or medicine to them.

\subsubsection{Identifying complicated and uncomplicated malaria}

About 63\% (39/62) of the respondents could accurately define complicated malaria and uncomplicated malaria. Out of this number, 56.4\% (22/39) and 35.9\% (14/39) were trained Over-the-Counter Medicine sellers and trained counter assistants respectively. About 26\% (6/23) of the respondents who has not participated malaria training in the past two years could not differentiate between complicated and uncomplicated malaria. About $98 \%(61 / 62)$ of the respondent mentioned at least one symptom of uncomplicated malaria. $46.8 \%(29 / 62)$, and 
9.7\% (6/62) respondents mentioned headache and fever respectively as a symptom of uncomplicated malaria. $38.7 \%(24 / 62)$ respondents mentioned at least four accurate signs and symptoms of uncomplicated malaria. 23 out of the 24 respondents were trained OTC medicine sellers and trained counter assistants.83.6\% (51/61) of respondents could mentioned at least one symptom of complicated malaria. 11.5\% (7/61),11.5\% (7/61), 9.8\% (6/61) and $8.2 \%$ $(5 / 61)$ of respondents mentioned jaundice or yellowish eye, high fever, dark colored urine and anemia respectively as signs and symptoms of complicated malaria. 42.6\% (26/61) of respondents mentioned at least four accurate signs and symptoms of complicated malaria. All the 26 respondents were trained OTC medicine sellers and trained counter assistants. Six (6) respondents representing $9.8 \%$ of respondents could not mention a sign and symptom of complicated malaria. All of them were not trained OTC medicine sellers none trained counter assistants. Table 4 presents responses on symptoms of uncomplicated and complicated malaria. Fifty (57) respondents representing 92.4\%, would refer patient with complicated malaria right away to the nearest health facility for treatment. Two respondents $(3.3 \%)$ would give the patient rectal suppository and refer him/her to the nearest health facility. One respondent answered "I don't know what to do for a patient with complicated malaria".

\subsubsection{Treating uncomplicated malaria}

$92 \%(57 / 62)$ of the respondents mentioned ACTs as the recommended drugs for treating uncomplicated malaria. Apart from ACTs, respondents also stock and dispense other antimalarial medicines. 43.5\% (27/62), 38.7\%(24/62), 30.65\% (19/62) and 26\% (16/62) mentioned they stock and dispense quinine (quinine syrup for infants, tablet for adult), monotherapies (specifically amodiaquine syrup for infants), sulphadoxine pyrimethamine (SP) and herbal antimalarial mixtures for treating uncomplicated malaria. No respondent stated Chloroquine for treating malaria (Figure 2). About 65.6\% (40/61) of respondents often recommend $\mathrm{AL}$ as the first choice for treatment of uncomplicated malaria. Reasons attributed to this include, patients tolerate it better than other ACTs, most preferred by clients, it is very effective, easily available and accessible in the market. $24.6 \%(15 / 61)$ of respondents often recommend $\mathrm{AS} / \mathrm{AQ}$ to patients due to its effectiveness in treating uncomplicated malaria. $6.6 \%$ $(4 / 61)$ often recommend SP for treating uncomplicated malaria. Reasons attributed this action are; nonavailability of subsided ACTs and the high cost of available ACTs and some clients insist on SP using for malaria treatment (Figure 3). 69.4\% (43/62) of respondents dispense antimalarial base on the patient's age, $19.4 \%(12 / 62), 4.8 \%(3 / 62)$ and $4.8 \%(3 / 62)$ of respondents dispense antimalarial base on patient's weight and age, actual weight of patient and base on Clinician's prescription respectively (Figure 4).

55 respondents (90\% of 61 respondents) who often recommend ACTs for patients, described the treatment dose of both AL and AS/AQ as; "4tablets twice daily (morning and evening) for 3 days for adults" and " 2 tabs AL for day one should be taken 8 hours interval". The 4 respondents who often recommend SP to patients, described the treatment of SP as " 3 tablets single dose"

Barely $4 \%(4 / 61)$ of the respondents stated that "the first dose of twice daily (morning and evening) for 3days".

Table 4. Responses on Symptoms of uncomplicated and complicated malaria

\begin{tabular}{|c|c|c|c|c|}
\hline Variable & $\begin{array}{l}\text { PC Trained } \\
\text { OTCMS } \\
{[\mathrm{N} 1=29]}\end{array}$ & $\begin{array}{l}\text { Counter } \\
\text { Assistant } \\
{[\mathrm{N} 2=22]}\end{array}$ & $\begin{array}{l}\text { Not } \\
\text { Qualified } \\
\text { OTCMS } \\
{[\mathrm{N} 3=11]}\end{array}$ & $\begin{array}{l}\text { Total } \\
{[\mathrm{N}=62]}\end{array}$ \\
\hline \multicolumn{2}{|l|}{ Freq. (\%) } & Freq. (\%) & Freq. (\%) & Freq. $(\%)$ \\
\hline \multicolumn{5}{|c|}{ Symptoms of Uncomplicated malaria } \\
\hline $\begin{array}{l}\text { A. Headache and } \\
\text { Body pains }\end{array}$ & $9(31)$ & $12(54.5)$ & $8(72.7)$ & $29(46.8)$ \\
\hline B. Bitter taste in & $1(3.4)$ & $0(0)$ & $0(0)$ & $1(1.6)$ \\
\hline
\end{tabular}


South American Journal of Clinical Research

Volume 3, Issue 1, 2016

\begin{tabular}{|l|l|l|l|l|}
\hline mouth & \multicolumn{1}{|l|}{} & & \\
\hline C. Fever & $4(13.8)$ & $1(4.5)$ & $2(18.2)$ & $7(11.3)$ \\
\hline D. Chills/Shivering & $1(3.4)$ & $0(0)$ & $0(0)$ & $1(1.6)$ \\
\hline $\begin{array}{l}\text { Stated all the above } \\
\text { (A -D) }\end{array}$ & $14(48.3)$ & $9(40.9)$ & $0(0)$ & $23(37.1)$ \\
\hline Don't know & $0(0)$ & $0(0)$ & $1(9.1)$ & $1(1.6)$ \\
\hline Symptoms of Complicated Malaria & $\mathrm{N} 1=29$ & $\mathrm{~N} 2=22$ & $\begin{array}{l}\mathrm{N} 3=10 *(1 \\
\text { missing) }\end{array}$ & $\mathrm{N}=61$ \\
\hline $\begin{array}{l}\text { Jaundice and } \\
\text { yellow eye }\end{array}$ & $3(10.3)$ & $3(13.6)$ & $1(10)$ & $7(11.5)$ \\
\hline \multicolumn{1}{|l}{ High fever } & $1(3.4)$ & $4(18.2)$ & $2(20)$ & $7(11.5)$ \\
\hline $\begin{array}{l}\text { Dark coloured } \\
\text { urine }\end{array}$ & $2(6.9)$ & $4(18.2)$ & $0(0)$ & $6(9.8)$ \\
\hline Anaemia & $2(6.9)$ & $2(9.1)$ & $1(10)$ & $5(8.2)$ \\
\hline $\begin{array}{l}\text { Stated at least 4 } \\
\text { corrected } \\
\text { symptoms }\end{array}$ & $18(62.1)$ & $8(36.4)$ & $0(0)$ & $26(42.6)$ \\
\hline $\begin{array}{l}\text { Stated at least one } \\
\text { correct symptom }\end{array}$ & $26(89.7)$ & $21(95.5)$ & $4(40)$ & $51(83.6)$ \\
\hline Don't know & $0(0)$ & $0(0)$ & $6(60)$ & $6(9.8)$ \\
\hline
\end{tabular}

Antimala rial Medicine Stock and

Dispense by Respondents

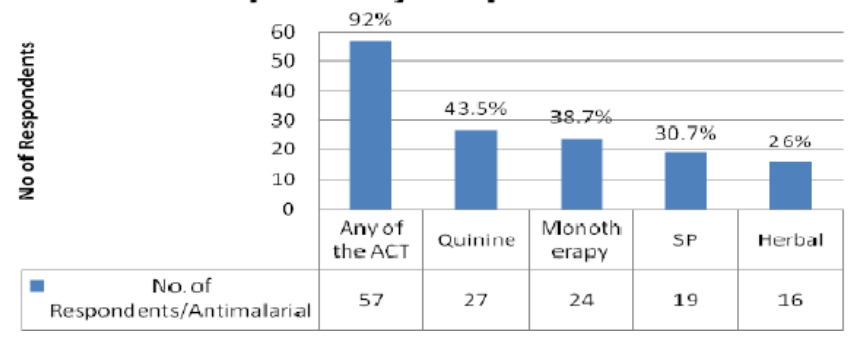

Figure 2. Antimalarial Medicine Stock and Dispense by Respondent

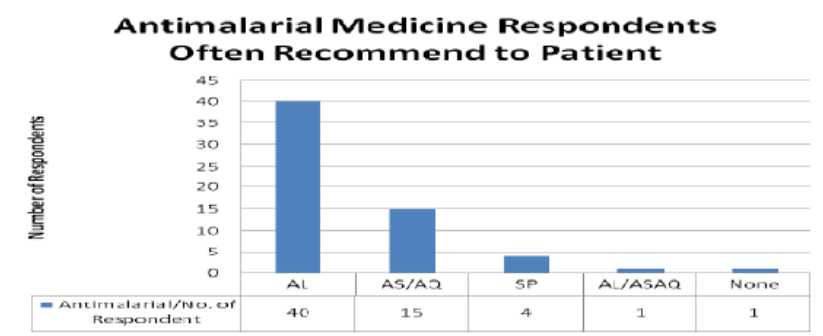

Figure 3: Antimalarial medicine Respondents often recommend to patients 


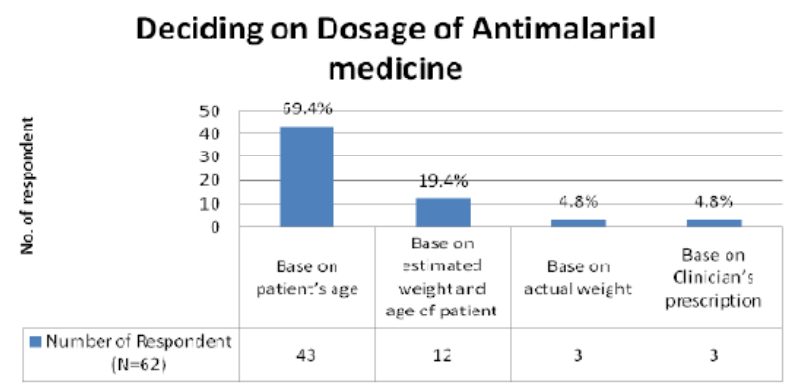

Figure 4. Deciding on Dosage of Antimalarial medicine

\section{Discussion}

\subsection{Malaria transmission, prevention, diagnosis and treatment}

This study revealed that the knowledge of malaria transmission and prevention among OTC medicine sellers and assistants was very high. About $97 \%$ of respondents stated " bite of mosquito" as the means by which one get malaria. Majority (73\%) of OTC medicine sellers and assistants advice clients and patients to sleep in LLIN and use insecticide spray and repellent to prevent malaria. This finding is in line with a similar study conducted by Buabeng 2010 in the Ashanti and the Northern regions and by Danquah, 2010 in the Ashanti region. However, only $26.2 \%$ of OTC medicines sellers use the rapid diagnostic test (RDT) kit to diagnosis and confirm malaria. This implies about $74 \%$ of service providers use either clinical symptoms $(54.1 \%)$ or assumption "try and error" to diagnose malaria. This is not in compliance with the current WHO Guidelines for Treatment of Malaria, 2015. This guideline recommends that in all settings all cases of suspected malaria should be confirmed with a parasitological test (microscopy or RDT). Danquah 2010 found same result in a similar study in the Ashanti region. There was a significant difference $(\mathrm{p}<0.05)$ between malaria diagnosis practice of OTC medicine sellers who had participated in malaria training within the past 2 years and those who had not. An OTC medicine seller who has participated in malaria training within past 2 years was more likely to use RDT to diagnose malaria than an OTC medicine sellers who has not. This study revealed that majority $(69.4 \%)$ of OTC medicine sellers decide on the dosage of antimalarial medicine for treatment base on the patient's age. Only $19.4 \%$ and $4.8 \%$ of them decide on dosage base on the estimated weight and age and actual weight of the patient. This is attributed to the fact that most OTC medicine sellers do have weighing scale and also very few treat malaria according to the recommended guidelines.

\subsection{Identifying uncomplicated and complicated malaria and IPT}

Over $60 \%$ of the OTC medicine sellers accurately defined uncomplicated and complicated malaria. Majority $98 \%$ and $83.6 \%$ of respondents could identify at least one symptom of uncomplicated and complicated malaria respectively. This study also revealed that majority (92\%) of OTC medicine sellers know that ACT is the recommended medicine for treating uncomplicated malaria. Also $92.4 \%$ would refer patient with complicated malaria to the nearest health facility for treatment. Buabeng 2010 also found that many medicine outlets (OTC medicines sellers and community pharmacists) could identify cases of both uncomplicated and complicated malaria.

Approximately $75 \%$ of OTC medicine sellers knows about Intermittent Preventive Therapy (IPT) for pregnant women and they know sulphadoxine pyrimethamine (SP) is the medicine for IPT. Also $78.7 \%$ of respondents often advice pregnant women who report to their shop for malaria treatment to go to hospital for appropriate care. Increase and improve awareness creation and training in malaria control would have greater impact in the knowledge and skills of OTC medicine to accurately identify uncomplicated and complicated malaria. 


\subsection{Antimalarial medicine stock and dispense to patients by OTC medicine sellers}

Per the national antimalarial drug policy and the WHO Guidelines for Treatment of malaria, 2015, ACT is the recommended drug for the treatment of uncomplicated malaria. Monotherapies, SP, quinine and herbal are not recommended for the treatment of uncomplicated. This study showed that $95 \%$ of respondents stock and sell ACTs. Among the ACTs, Artemether Lumefantrine (AL) is one most (65.6\%) respondents recommend to patient for malaria treatment, followed by Artesunate Amodiaquine (AS/AQ), See figure 3. However as high as $43 \%, 38.7 \%, 30.7 \%$ and $26 \%$ of respondents were found to stock and sell quinine, monotherapies, SP and herbal respectively to treat uncomplicated malaria. Reasons stated by most of these OTC medicine sellers included, "some clients/patients insist on using the SP, monotherapies, herbal and the quinine" , "some clients/patients could not afford ACT" and "we often run out of stock of the affordable medicine facility-malaria (AMFm) branded ACT and we are left with no option than to sell these ones". This implies that the availability of ACT in an OTC medicine shop does not guarantee it been used for the recommended treatment. This finding concurs with that of Danquah 2010, where $71.9 \%$ of LCS shops had only monotherapies among which $28.1 \%$ had only SP. There is the need for effective and strong pharmacovigilance system and monitoring by the Pharmacy council and District Health team to ensure compliance. There is also the need to strengthen the existing systems and build news effective structures there will ensure easier access to quality and affordable ACTs at the community level. This study revealed that $90 \%$ of OTC medicine sellers could not explain appropriately the treatment regimen of the ACTs, especially the treatment regimen of AL. Most of them describe the treatment regimen of AL in the same way AS/AQ is taken. Barely $4 \%$ of OTC medicine sellers stated " the first dose of AL for day one should be taken 8 hours interval".

\section{Conclusion and recommendation}

\subsection{Conclusion}

Trained OTC medicine and trained assistants have better knowledge of malaria and could diagnose and manage malaria cases better than the non trained OTC medicine sellers and assistants. The education status of an OTC medicine seller or an assistants is bonus to his/her knowledge and skills in malaria control and management. Recent training in malaria control and management has good effect on the knowledge and practice of an OTC medicine seller and their assistants. OTC Medicine Sellers who has participated in malaria training within the past 2 years is more likely to use RDT to diagnose and confirm suspected malaria

Quite a high number of OTC medicine sellers still stock and dispense non-recommended antimalarial drugs.

\subsection{Recommendation}

Periodic malaria training of all OTC medicine sellers which focuses on effective diagnosis and treatment would significantly improve their knowledge and skills in malaria management and help control malaria at the community level.

\section{Acknowledgment}

Authors would like to acknowledge the District Directors of Health Services and the OTC medicine sellers associations of the Pru, Sene and Atebubu-Amantin districts for offering us the permission to conduct this research in their districts. We would also like to express our appreciation to every OTC medicine sellers who voluntarily consented to participate in this research.

\section{References}

[1.] Addai-Mensah $\mathrm{O}$,: Establishment of a phage display platform for the isolation of Plasmodium falcipurum, monoclonal antibodies, Research thesis, RWTH Aachen University: page 1, October, 2014

[2.] Affordable Medicine Facility-malaria (AMFm) first-line buyers list, Global Fund, 
September, 2013.

[3.] Ahorlu CK, Dunyo SK, Afari EA, Koram KA, Nkrumah FK: Malaria-related beliefs and behaviour in southern Ghana: implications for treatment, prevention and control. Trop Med Int Health 2: 488-499,1997

[4.] Buabeng K.O, The Role of the Pharmaceutical Sector in malaria Control in Ghana, Faculty of Health Science, University of Eastern Finland 2010

[5.] Cohen JC, Gyansa-Lutterodt M, Torpey K, Esmail LC, Kurokawa G: TRIPS, the Doha Declaration and increasing access to medicines: policy options for Ghana. Global Health 1: 17,2005

[6.] Danquah D.A , Evaluating Access to Anti-Malaria medicine and quality of Service delivery by Community Pharmacies and Licensed Chemical Shops in Ashanti Region, Ghana 2010

[7.] FHI 360, OTC medicine sellers identification and selection exercise, Pru, Sene and Atebubu-Amantin districts, 2015, Ghana

[8.] Gallup, JL; Sachs, JD. The economic burden of malaria. Am J Trop Med Hyg. 2001;64:85-96. [PubMed]

[9.] Ghana district map -www.ghanadistricts.com/home) accessed on May $5^{\text {th }}, 2015$

[10.] Global Fund AMFm pricing, August 2010 report

[11.] Goodman C, Brieger W, Unwin A, Mills A, Meek S, Greer G: Medicine sellers and malaria treatment in sub-Saharan Africa: what do they do and how can their practice be improved? Am J Trop Med Hyg 77 (Suppl 6): 203-218, 2007a

[12.] Health Partners Ghana. Management of malaria by care givers and licensed chemical sellers in the Ashanti Region, Ghana. A baseline survey of the MAM Project October, 2008.

[13.] Ministry of Health (GNDP) Ghana: Ghana national drug policy, second edition 2004. Accessed May $4^{\text {th }} 2015$ from

http://who.int/countries/gha/publications/Ghana_National_DrugPolicy_2nd_Edition.pdf

[14.] Pharmacy Council, Ghana: Practice standards for pharmacist and licensed chemical sellers, 2004.

[15.] Republic of Ghana (Pharmacy ACT 489): Pharmacy Council ACT, 1994

[16.] WHO The Roll Back Malaria strategy for improving access to treatment through home management of malaria. World Health Organization. 2005.

[17.] World Health Organization: Guidelines for Treatment of Malaria, 2015

[18.] World Health Organization: World Malaria Report 2015. 